\title{
Physiological consequences of social descent: studies in Astatotilapia burtoni
}

\author{
Victoria N Parikh ${ }^{\mathbf{1}}$, Tricia Clement ${ }^{\mathbf{2}}$ and Russell D Fernald ${ }^{\mathbf{1}, \mathbf{2}}$ \\ ${ }^{1}$ Program in Human Biology and ${ }^{2}$ Department of Biological Sciences, Stanford University, Stanford, California 94305-5020, USA \\ (Requests for offprints should be addressed to R D Fernald; Email: rfernald@stanford.edu)
}

\begin{abstract}
In many species, social interactions regulate reproductive capacity, although the exact mechanisms of such regulation are unclear. Since social stress is often related to reproductive regulation, we measured the physiological signatures of change in reproductive state as they relate to short-term stress and the stress hormone cortisol. We used an African cichlid fish, Astatotilapia burtoni, with two distinct, reversible male phenotypes: dominant (territorial, T) males that are larger, more brightly colored, more aggressive, and reproductively competent and non-dominant males (non-territorial, NT) that are smaller, camouflage colored, and have regressed gonads. Male status, and hence reproductive competence, depends on social experience in this system. Specifically, if a T male is placed among larger male fish, it quickly becomes NT in behavior and coloration, but complete regression of its reproductive axis takes ca. 3 weeks (White et al. 2002). Reproduction in all vertebrates is controlled by the
\end{abstract}

hypothalamic-pituitary-gonadal axis in which the key signaling molecule from the brain to the pituitary is GnRH1. Here, we subjected $\mathrm{T}$ males to territory loss, a social manipulation which results in status descent. We measured the effects of this status change in levels of circulating cortisol and testosterone as well as mRNA levels of GnRH1 and GnRH receptor-1 (GnRH-R1) in the brain and pituitary, respectively. Following short-term social suppression $(4 \mathrm{~h})$, no change was observed in plasma cortisol level, GnRH1 mRNA expression, GnRH-R1 mRNA expression, or plasma testosterone level. However, following a somewhat longer social suppression $(24 \mathrm{~h})$, cortisol and GnRH1 mRNA levels were significantly increased, and testosterone levels were significantly decreased. These results suggest that in the short run, deposed $\mathrm{T}$ males essentially mount a neural 'defense' against loss of status.

Journal of Endocrinology (2006) 190, 183-190

\section{Introduction}

How do social conditions interact with physiological processes to influence behavior? Although a complete answer to this question remains unknown, it is clear that behavioral output results from complex interactions that cannot be understood simply as stimulus-response systems, but depend on more complex combinatorial mechanisms. Two key elements influencing behavior in a social system are social context and circulating hormone levels (Fernald 2002, Oliveira et al. 2002, McEwen \& Wingfield 2003, Sapolsky 2005). To understand how social conditions influence physiology, we analyzed hormone levels, social context, and reproductive physiology following defined social stress in semi-natural conditions using an African cichlid fish, Astatotilapia burtoni.

A. burtoni has a two-tiered social system in which males can be either dominant (territorial males, $\mathrm{T}$ males) or non-dominant (NT males), and importantly, these states are reversible. T males are brightly colored, physically larger, aggressively defend a territory, and have fully spermiated testes, as contrasted with non-territorial males (NT males), which are camouflaged, smaller, school with female fish, and are not reproductively active (Fernald \& Hirata 1977). Corresponding to these substantial behavioral differences are a suite of physiological and molecular differences (reviewed in Fernald 2002).

In $A$. burtoni, as in all the vertebrates, reproduction is ultimately controlled by the brain via the hypothalamicpituitary-gonadal (HPG) axis. In the hypothalamus, neurons release gonadotropin-releasing hormone 1 (GnRH1), a signaling peptide that stimulates the release of gonadotropins from the pituitary, which in turn causes the gonads to mature and produce androgens. Expression of GnRH1 and its receptor in the pituitary is strongly up-regulated in $\mathrm{T}$ males as compared to NT males (White et al. 2002, Au et al. 2006). A. burtoni males change between T and NT states depending on the social environment. When a $\mathrm{T}$ male is placed with significantly larger fish, it assumes NT male status quickly in both behavior and coloration. However, the loss of reproductive competence takes ca. 3 weeks after loss of territory (White et al. 2002). In contrast, NT males ascending socially to become $\mathrm{T}$ males will show an eyebar and aggressive behavior almost immediately (Burmeister \& Fernald 2005), and will shift physiologically to territorial status in ca. 1 week (White et al. 2002). 
Several investigators have identified a direct link between social status and the stress hormone cortisol (Blanchard et al. 1993), which is one output of the hypothalamic-pituitaryadrenal axis. When an animal is under stress, the hypothalamus releases corticotropin-releasing hormone to the pituitary, which in turn releases adrenocorticotropic hormone $(\mathrm{ACTH})$ into the blood stream. At the adrenal cortex, ACTH causes the release of cortisol through which it mobilizes energy stores, increases heart rate, slows digestion and stimulates gluconeogenesis (reviewed in Becker et al. 1992). Thus, the activity of cortisol directs metabolic energy away from long-term physiological projects such as reproduction and toward the short-term goal of combating the stressor (Sapolsky 1993a). Animals under chronic stress may have these long-term, metabolically expensive activities inhibited indefinitely, corresponding to reproductive regression. This regression is observed in $\mathrm{T}$ males following the loss of a territory and ensuing descent in status.

The status differences observed in $A$. burtoni and other species with social stratification correspond to chronic social stress experienced by lower as compared with higher ranking individuals (Manogue et al. 1975, De Goeij et al. 1992, Blanchard et al. 1993, Sapolsky 1993b). However, the relationship of cortisol to social status in $A$. burtoni appears to depend not only on the status of the individual, but also on the social community and maturational state of the animals. For example, when males are housed in T-NT social pairs, GnRH neuronal soma size differences are significantly up-regulated in Ts vs NTs and differences in cortisol are statistically significant in older fish that lived as stable pairs for 2 weeks (Fox et al. 1997). Among younger fish and in the first week of such pairings, cortisol levels were significantly more variable and showed only a trend towards higher values in NT males. However, when animals are placed into a novel group setting, significant, stable T-NT cortisol differences are clearly evident at approximately 7 weeks, once the community has stabilized (Fox et al. 1997). Thus, in the short run, stress profiles and GnRH neuronal soma sizes may be uncoupled in some situations. T-NT dyads, a context that produces extreme behavioral status differences, may indicate other regulatory systems related to individual social experience not directly tied to cortisol.

Here, we subjected individual T males to very short $(4 \mathrm{~h})$ and longer ( 1 day) stress of territory loss that ultimately produces a status shift from $\mathrm{T}$ to NT. We measured circulating androgen and cortisol levels and GnRH1 and GnRH receptor-1 (GnRHR1) mRNA levels in the brain and pituitary respectively at 4 and $24 \mathrm{~h}$ after social descent. Our data suggest that physiological changes occurring during the first day of status descent differ from those observed in the long term, implying an immediate response to territory loss that is not sustained.

\section{Materials and Methods}

\section{Subjects}

We used 16 A. burtoni $\mathrm{T}$ males, originally derived from wildcaught stock in Lake Tanganyika, East Africa (Fernald \&
Hirata 1977). Prior to the experiment, fish were kept in aquaria under environmental conditions similar to those in nature $\left(28^{\circ} \mathrm{C}, \mathrm{pH} 8\right.$ and a $12 \mathrm{~h}$ light: $12 \mathrm{~h}$ darkness cycle with full spectrum illumination). Fish were fed cichlid pellets and flakes (AquaDine; Healdsburg, CA, USA) each morning ad libitum. Gravel covered the bottom and terracotta pots were placed in each aquarium to facilitate establishment of territories. Each community tank held 2-4 $\mathrm{T}$ males, 2-4 NT males, and 5-12 females. Individual animals were tagged with a combination of colored beads attached with a thin nylon string just below the dorsal fin to allow individuals to be identified for behavioral observations. Animals were treated at all times in accordance with Stanford's Administrative Panel for Laboratory Animal Care approved animal treatment policies.

\section{Procedure}

Each subject in the group tank was observed for $3 \mathrm{~min}$, three times per week for at least 1 week prior to selection. Behavioral patterns characteristic of $\mathrm{T}$ or NT males were recorded, including establishment and defense of a territory, coloration, and aggressive and sexual behavioral displays, in order of importance for this study (Fernald \& Hirata 1977). Aggressive behaviors include: border threat displays (gill flaring and swimming rapidly in the direction of another male across an apparent territory border), carouseling (biting and attacking another male fish during a fight), and chasing or biting other fish. Sexual behaviors include courting of females (moving tail and end of body in solicitation), digging (each instance in which the male picks up a gravel in its mouth and spits it out), and spawning. Behaviors that indicated the NT status were fleeing from an attack and schooling with females. Subjects were assigned a status according to these behavioral observations. Due to dynamic social conditions, the T males often defend poorly defined or variable territories. Thus, to ensure that males were of full $\mathrm{T}$ status, only those defending a physically identifiable territory were considered territorial.

Eight of these T males were randomly assigned to the group to be sacrificed after a short time (e.g., 4 h: four experimental males and four control males) and eight $\mathrm{T}$ males assigned to the group to be sacrificed after a longer time (e.g., $24 \mathrm{~h}$; four experimental males and four control males). On the evening prior to subjecting the $\mathrm{T}$ male to social descent, an individual male (focal male) was moved to the test tank for habituation. The test tank was bisected by an opaque barrier, creating two equal-sized hemi-tanks. In one hemi-tank, each focal male was housed with two females. For animals assigned to experimental conditions, an exceptionally large $\mathrm{T}$ male (stimulus male) was housed with six females on the opposite side of the opaque barrier. At the time of exposure (at $2400 \mathrm{~h}$ ( $4 \mathrm{~h}$ group) or $1600 \mathrm{~h}$ ( $24 \mathrm{~h}$ group)), the focal male was transferred into the territory of the stimulus male by being placed into the other hemi-tank. Being placed in this context with a large $\mathrm{T}$ male, it mimicked the loss of the focal male's territory. In the control condition, no $\mathrm{T}$ male was housed in 
the opposite tank, leaving only six females. Since no dominating male was present, this did not mimic a territory loss. For comparison, this group acts as a control, allowing the measurement of the effects of the transfer without the sustained stress of territory loss, so that we might be sure that the stress experienced by the experimental group is not merely from the transfer. Following the exposure time (4 or $24 \mathrm{~h}$ ), plasma was drawn and the animal sacrificed.

\section{Circulating hormone levels}

Immediately before sacrifice, blood samples (between 50 and $100 \mu \mathrm{l})$ were taken from each male using heparinized capillary tube butterfly needle. Blood was collected from the first caudal vein and centrifuged for $3 \mathrm{~min}$ at 13000 r.p.m. to separate plasma from red blood cells. Blood samples were obtained within the first $3 \mathrm{~min}$ following capture to ensure that any acute stress associated with the blood draw itself did not affect the obtained cortisol levels (Fox et al. 1997). Plasma was then isolated and stored at $-80{ }^{\circ} \mathrm{C}$ until assayed. After blood collection, subjects were immediately returned to their community tanks.

\section{Cortisol assay}

Cortisol concentration was measured in the plasma samples using an ELISA (Cortisol Correlate-EIA kit; Assay Designs, Inc., Ann Arbor, MI, USA). Plasma samples were diluted in assay buffer at the ratio of 1:30 and the kit protocol strictly followed. The reactions were performed in 96-well plates, which were read with a conventional plate reader at $405 \mathrm{~nm}$ (Vmax Microplate Reader, Molecular Devices, Sunnyvale, CA, USA). To normalize our cortisol data distribution, we transformed measurements of the circulating cortisol using the natural logarithm function.

\section{Testosterone assay}

Plasma testosterone concentration was measured using an ELISA (Testosterone Correlate-EIA kit; Assay Designs, Inc.). Plasma samples were thawed and diluted in a 1:30 solution with assay buffer and placed in normal 64-well plates. The ELISA kit protocol was then strictly followed with the exclusion of heating the plate to $37^{\circ} \mathrm{C}$ and placing it on a plate shaker during the second incubation instead of letting it sit at room temperature. In validation trials with $A$. burtoni plasma, this step was found to greatly reduce interwell variability. Plates were read at $405 \mathrm{~nm}$ (Vmax Microplate Reader; Molecular Devices). To normalize circulating testosterone distribution, we transformed the data using a square root function before statistical testing.

Though 11-ketotestosterone (11-KT) is typically more abundant than testosterone, we have demonstrated that in this species, testosterone levels in dominant versus submissive males mirror 11-KT levels (Parikh et al. 2006), and so here we use the testosterone level as a proxy for all circulating androgen levels.
A review of teleost androgens reports that in salmonids, 11-KT and testosterone both peak in the breeding season (Borg 1994).

\section{Gene expression measurement}

Levels of GnRH1 mRNA in the brain and GnRH-R1 mRNA in the pituitary were assayed using quantitative realtime RT-PCR (quantitative RT-PCR).

\section{Tissue preparation}

Tissue was homogenized in Trizol reagent $(1 \mathrm{ml}$ for brain and $850 \mu$ for pituitaries; Invitrogen) using a Tissue Tearor (Biospec Products, OK, USA) for approximately $1 \mathrm{~min}$, or until no visible tissue debris existed in solution. RNA was extracted from this homogenate using a volume of chloroform, $0 \cdot 2$ times the volume of Trizol used. Isopropyl alcohol was used to precipitate the RNA in the amount of 0.5 times the amount of Trizol used. The RNA was then washed with an amount of $75 \%$ ethanol equal to the original Trizol amount. The RNA pellet was re-suspended in RNase-free water $(20 \mu \mathrm{l}$ for pituitary and $50 \mu \mathrm{l}$ for brain) and stored at $-80^{\circ} \mathrm{C}$ for not more than 5 days. The re-suspended RNA was treated with Turbo DNase kit (Ambion, Austin, TX, USA) to remove any DNA from the solution. The concentration of the RNA in this solution was determined using spectrophotometric readings at 260/280 nm (Beckman). To make cDNA, either $0 \cdot 3,0 \cdot 5$, or $1 \mu \mathrm{g}$ RNA was used with iScript cDNA synthesis kit (BioRad).

\section{Gene expression levels: real-time PCR}

Primers for GnRH1 (GenBank accession CN469235) and GnRH-R1 (GenBank accession AY705931) were designed from full-length sequences (Chen \& Fernald 2006, Grens et al. 2005) using Oligo 6.7 (MBI, Cascade, CO, USA) and were synthesized commercially (Invitrogen). GnRH1 primers were: upper 5'-CAG-ACA-CAC-TGG-GCA-ATA-TG-3' and lower 5'-GGC-CAC-ACT-CGC-AAG-A-3'. GnRH-R1 primers were: upper $5^{\prime}$-GCG-TGC-TCA-GTT-CCGAGT-T- $3^{\prime}$ and lower $5^{\prime}$-CGC-ATC-ACC-ACC-ATACCA-CT- $3^{\prime}$. As an internal control for differences in cDNA synthesis, tissue volume and loading during the PCR, each template was also tested for the presence of actin mRNA transcripts, as actin is a ubiquitously expressed housekeeping gene, which serves as an adequate control. Actin primer sequences were: upper 5'-GGC-CCA-GAG-CAA-GAGAGG-TAT-C- $3^{\prime}$ and lower $5^{\prime}$-GAT-GCC-AGA-TCTCTTCT-CCA-TGT-CAT-CC- $3^{\prime}$.

First, primers were diluted with nuclease-free water to $10 \mathrm{mM}$ concentration and the cDNA sample was diluted with nuclease-free water (Ambion) at a ratio of $1: 3$ for $0 \cdot 3 \mu \mathrm{g}, 1: 5$ for $0.5 \mu \mathrm{g}$, and 1:20 for $1 \mu \mathrm{g}$ preparations. Quantitative RTPCR was performed using $30 \mu$ triplicate reactions with $1 \times$ IQ SYBR Green Supermix (Bio-Rad), $0.5 \mu \mathrm{M}$ of each primer, and $0.5 \mathrm{ng} / \mu \mathrm{lDNA}$ for each sample and each gene on the MyIQ Single-Color Real-Time PCR Detection 
System (BioR ad). The PCR was run with the following PCR parameters: $5 \mathrm{~min}$ at $95^{\circ} \mathrm{C}, 45$ cycles of $30 \mathrm{~s}$ at $95^{\circ} \mathrm{C}, 30 \mathrm{~s}$ at $60{ }^{\circ} \mathrm{C}$, and $30 \mathrm{~s}$ at $72{ }^{\circ} \mathrm{C}$, followed by melt curve analysis. We detected the fluorescence at $490 \mathrm{~nm}$ at the start of the annealing step $\left(60^{\circ} \mathrm{C}\right)$ in each cycle. Melt curves for PCR products showed two distinct peaks in each case, indicating purity of primers for both genes. In the case of GnRH-R1, only one peak appeared, which is to be expected, given the highly similar melting points of the GnRH-R1 and actin primers.

Raw fluorescent data (background subtracted data) provided by the MyIQ software (BioRad) were analyzed using the real-time PCR Miner program (Zhao \& Fernald 2005), which uses the resultant PCR efficiency and fractional cycle number of the threshold (CT) for gene quantification. All data are expressed as a ratio of gene of interest expression to actin expression.

\section{Statistical analysis}

A two-tailed $t$-test was used to compare means for all measures, and statistical significance set as $P<0 \cdot 05$. In the case of plasma hormone concentration, standard transformations were applied to the raw data to make their distributions approximately normal. Levene's test for heterogeneity of variance was used to assess the data distribution before and after transformation. This was done to ensure that a $t$-test could be used to reliably assess the statistical significance of data. For transformed data, none of the Levene's tests was significant at level $P=0 \cdot 05$, so we have no reason to expect large deviations from a normal distribution. For plasma cortisol level, the natural logarithm function was used to transform the data, and for plasma testosterone level, the square root function was used to transform data.

\section{Results}

Short-term social suppression $(4 \mathrm{~h})$

As seen in Fig. 1, there were no significant differences between experimental and control subjects, although GnRHR1 mRNA expression showed a trend towards increase in experimental animals $(P=0 \cdot 12)$ (two-tailed $t$-test). A regression analysis shows a trend suggesting that increased sample size might reveal up-regulation of GnRH-R1 expression in the experimental group $\left(R^{2}=0 \cdot 60\right)$.

\section{Longer-term social suppression (24h)}

After $24 \mathrm{~h}$ of sustained social stress, there is significant upregulation of circulating cortisol $(P=0 \cdot 01)$ and GnRH1 mRNA expression $(P=0 \cdot 02)$ as compared with controls (Fig. 2A and B).

For GnRH-R1 mRNA expression, a regression analysis revealed a trend suggesting that increased sample size might reveal a down-regulation of GnRH-R1 mRNA in the experimental group $\left(P=0 \cdot 12, R^{2}=0 \cdot 37\right.$; Fig. 2C). A twotailed $t$-test showed that experimental subjects had significantly lower levels of circulating testosterone than did control subjects $(P=0 \cdot 008$; Fig. $2 \mathrm{D})$. There is also a positive correlation between circulating testosterone level and GnRH-R1 mRNA expression $\left(R^{2}=0 \cdot 76\right.$; Fig. 3) as well as a positive correlation between plasma cortisol concentration and GnRH1 mRNA expression $\left(R^{2}=0 \cdot 70\right.$; Fig. 4).

\section{Discussion}

A. burtoni males have distinct behavioral and physiological phenotypes characterizing them as either T or NT males. Several different experiments in semi-natural conditions showed that these male phenotypes differ physiologically, particularly with respect to parameters of their reproductive systems. For example, T males in stable conditions have low cortisol (Fox et al. 1997) and have higher testosterone and 11KT levels (Parikh et al. 2006) as compared with NT males. In the HPG axis, T males have higher levels of the key signaling peptide, GnRH1 and its mRNA (White et al. 2002), higher levels of GnRH-R1 mRNA (Au et al. 2006), and larger gonads (Davis \& Fernald 1990) than NT males. Moreover, T male gonads contain mature sperm in contrast to NT males whose gonads contain largely immature sperm (Fraley \& Fernald 1982). Experiments designed to follow the time-course of transition between these two phenotypes revealed that ascent and descent each had different temporal trajectories for several of these parameters (White et al. 2002). Specifically, animals appear to ascend much faster than they descend in social status as reflected in their physiology and behavior. Here, we examined the physiological and behavioral consequences of imposed social descent from $\mathrm{T}$ to NT over a significantly shorter time period and found a novel physiological consequence of forced social descent.

After a 4-h social stress, we found that none of the output measures was significantly changed in socially suppressed males. However, in animals that experienced a somewhat longer sustained social stress for $24 \mathrm{~h}$, we found several differences. As expected, the circulating cortisol level increased significantly, while the circulating testosterone level dropped significantly, both of which are consistent with the steady-state differences measured between the $\mathrm{T}$ and NT phenotypes in longer-term experiments (Fox et al. 1997, Parikh et al. 2006). GnRH1 gene expression surprisingly increased significantly. Assuming that mRNA expression is a reliable marker of protein production, this change would ultimately produce a countervailing effect on the HPG axis compared with the regression in HPG physiology evident in decreased testosterone output. This could be interpreted as an attempt to counteract HPG regression, possibly via an alternate pathway.

Forcing a $\mathrm{T}$ male into the NT status has important consequences. When an animal is subjected to a change in its 
A

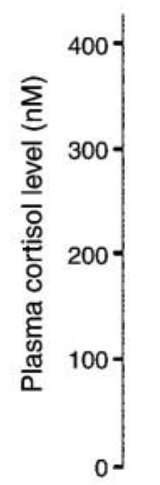

C

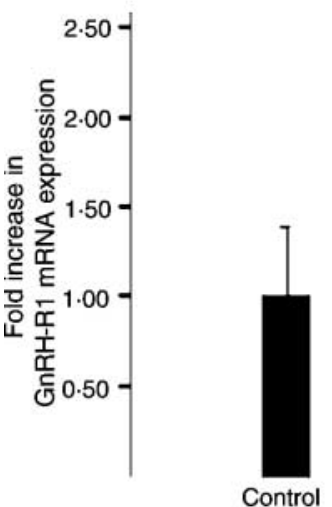

Plasma cortisol levels

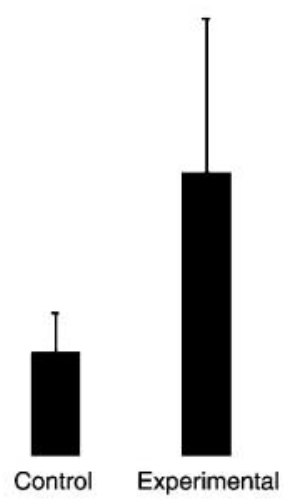

GnRH-R1 mRNA expression

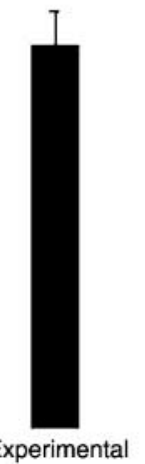

B

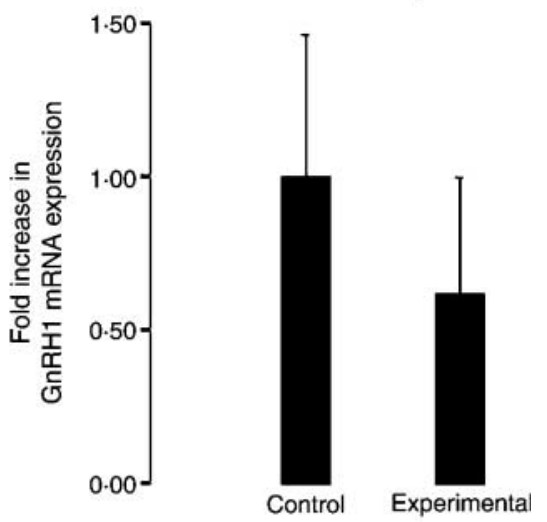

D

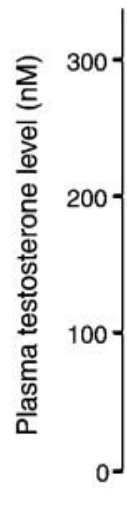

Plasma testosterone levels

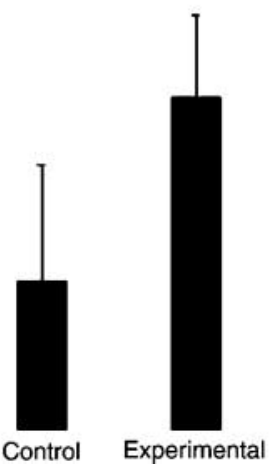

Figure 1 Effects of short-term $(4 \mathrm{~h})$ social suppression on plasma levels of (A) cortisol, (D) testosterone, and mRNA levels of (B) hypothalamic $\mathrm{GnRH} 1$, and (C) pituitary $\mathrm{GnRH}$ receptor-1 (GnRH-R1), none of which showed any significant difference between control and experimental animals. All mRNA data are expressed as fold increase with respect to control after normalization to actin mRNA expression. There is a trend toward an increase in GnRH-R1 expression (see Results). All data are represented as mean \pm s.E.M. (A) Experimental, $n=4$; control, $n=4 ; P=0.47$ (two-tailed $t$-test); (B) experimental, $n=4$; control, $n=4 ; P=0.55$ (twotailed $t$-test); (C) experimental, $n=2$; control, $n=3 ; P=0 \cdot 12$ (two-tailed $t$-test); (D) experimental, $n=3$; control, $n=4 ; P=0 \cdot 18$ (two-tailed $t$-test).

dynamic homeostatic equilibrium, whether social or physiological, it expends energy in an attempt to restore the original steady state, responding in one of three ways. The body can regain normal equilibrium once the stressor has ended, or it can enter an over- or under-aroused state if the stress is sustained. In the experimental paradigm used here, animals cannot regain normal equilibrium because the stressor persists and so these observations document the response of animals to an ongoing short-term stressor without respite.

One of the hallmarks of the response to stress is an attempt to maintain stability through change, termed allostasis (McEwen \& Wingfield 2003). The concept of allostasis refers to attempts to maintain homeostatic balance through accommodations in response to ongoing challenges. However, when the energetic costs of this readjustment outweigh energy intake (e.g., 'type 1' allostatic overload; McEwen \& Wingfield 2003), the animal must adjust by removing itself from its present life-cycle stage and retreat into a 'survival state.' Status loss in A. burtoni, moves the animal from a reproductive life-cycle phase to a non-reproductive state.

Glucocorticoids have been implicated as physiological and behavioral indicators of this change. For example, glucocorticoid response has been shown to be modulated by perceived control over a situation (Weiss 1971, Weiss et al. 1981). In particular, attention has been focused on cortisol for mediating behavioral effects, because this steroid hormone is released in response to numerous stressors and can cross the blood-brain barrier to influence behavior, whereas epinephrine cannot (Wendelaar Bonga 1997). Moreover, there are cortisol receptors in the brains of many species, including $A$. burtoni (Greenwood et al. 2003), implicating cortisol in behavior modulation in this system.

The unexpected finding here is the increase in GnRH1 mRNA levels together with the rise in circulating cortisol after 
A

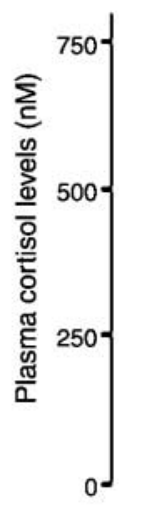

C

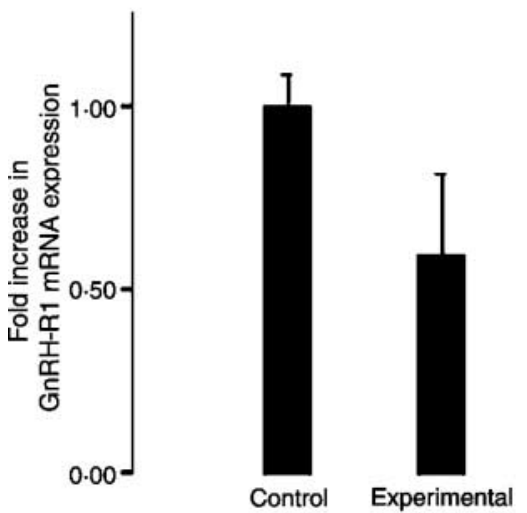

Plasma cortisol levels

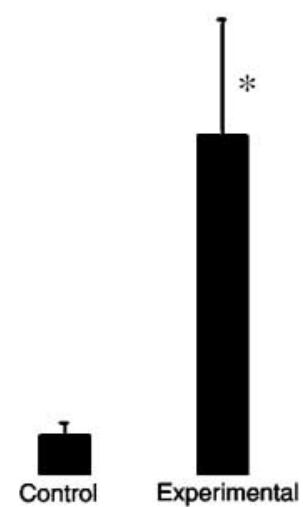

GnRH-R1 mRNA expression
B

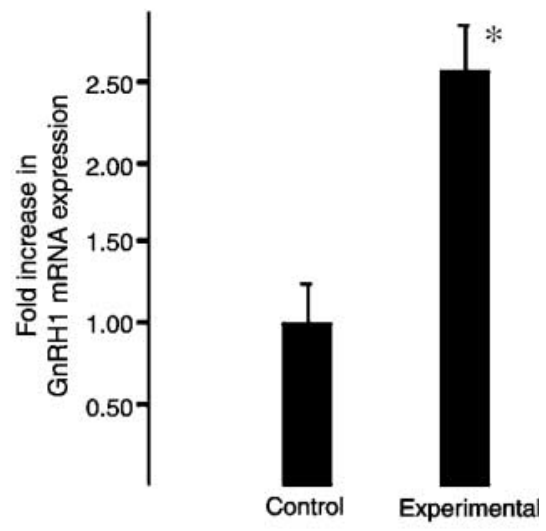

D

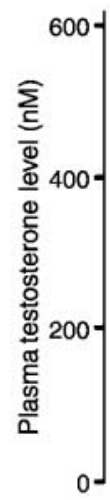

GnRH1 mRNA expression

Plasma testosterone levels

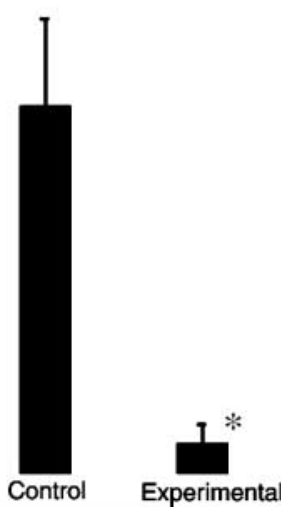

Figure 2 Effects of longer-term (24 h) social suppression on (A) plasma levels of cortisol, (D) testosterone, and mRNA levels of (B) hypothalamic $\mathrm{GnRH} 1$, and (C) pituitary $\mathrm{GnRH}$ receptor- 1 (GnRH-R1). Mean plasma cortisol level and GnRH1 mRNA level were significantly increased, mean plasma testosterone level decreased and there was no significant change in GnRH-R1 mRNA level. All mRNA data are expressed as fold increase with respect to control after normalization to actin mRNA expression. All data are represented as mean \pm S.E.M. (A) Experimental, $n=2$; control, $n=4 ; P=0 \cdot 01$ (two-tailed $t$-test); (B) experimental, $n=2$; control, $n=4 ; P=0.02$ (two-tailed $t$-test); (C) experimental, $n=3$; control, $n=4 ; P=0 \cdot 12$ (two-tailed $t$-test); (D) experimental, $n=3$; control, $n=4 ; P=0 \cdot 008$ (two-tailed $t$-test). * indicates statistical significance (see text).

$24 \mathrm{~h}$ of social stress (Fig. 2A). Further, $24 \mathrm{~h}$ after the onset of social stress, plasma cortisol is positively correlated to GnRH1 mRNA expression (Fig. 4). Cortisol has been shown in cell culture systems to down-regulate gene expression of both GnRH (Chandran et al. 1994) and GnRH receptor mRNAs (Maya-Nunez \& Conn 2003) in mammals. Moreover, in A. burtoni, in the steady state, the up-regulation of cortisol is correlated with down-regulation of GnRH1 (Fox et al. 1997) and GnRH1 mRNA (White et al. 2002). Thus, in the early stages of status descent, the up-regulation of GnRH1 mRNA suggests that the animals may be mounting a defense against social descent at the level of production of GnRH1 mRNA, the essential signal to the pituitary. Interestingly, testosterone output is down-regulated, reflecting a negation of the up-regulation of GnRH1. Since this GnRH1 effect is at the level of transcriptional regulation, we do not know whether there is a corresponding effect at the level of the synthesized protein.

In analyzing these data, there are two important considerations. First, there is growing evidence that fish can and do distinguish amongst social stressors. For example, animals observing other animals engaged in conflict show an increase in cortisol and testosterone (Oliveira et al. 1998, 2001), yet fish engaged in fighting with their own image in a mirror do not show a testosterone response (Oliveira et al. 2005). Further, in A. burtoni, social status correlates with different behavioral responses in an aggressor than in a subordinate. Social status and cortisol response may interact to produce direct versus displaced aggression in response to that 


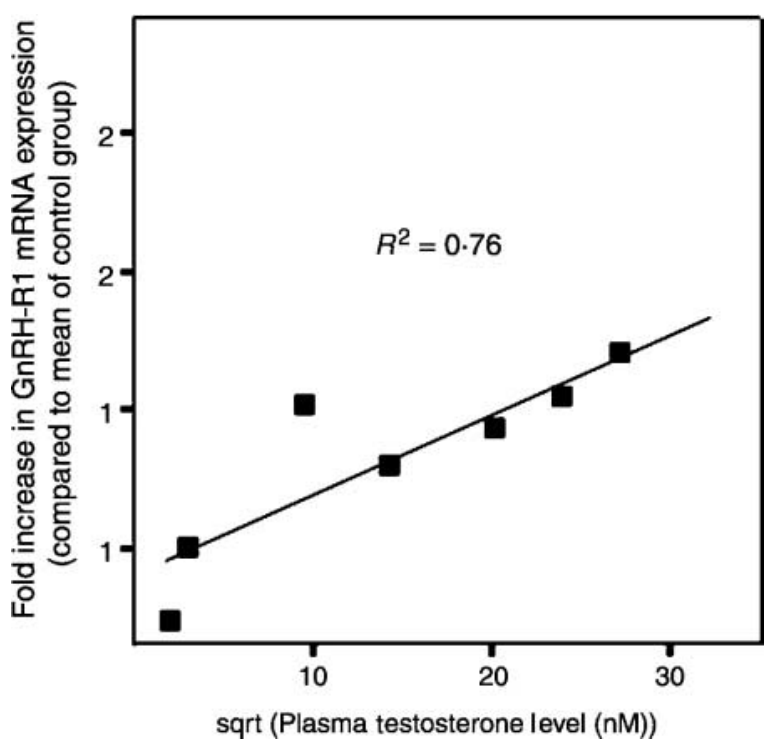

Figure 3 Correlation between plasma testosterone and GnRH-R1 mRNA levels in 24-h social suppression.

aggressor (Clement et al. 2005). This suggests that fish may have distinct behavioral coping strategies depending both on their own status and that of the aggressor, and that these may be reflected in physiology.

Secondly, dominant $A$. burtoni males mount a physiological defense against loss of status by increasing the mRNA levels for the key signaling peptide, GnRH1, while displaying high cortisol levels. This immediately suggests that the typical negative feedback effect of high cortisol on GnRH1 is countered and even reversed in $\mathrm{T}$ males during the initial hours following social descent. This reversal may reflect an

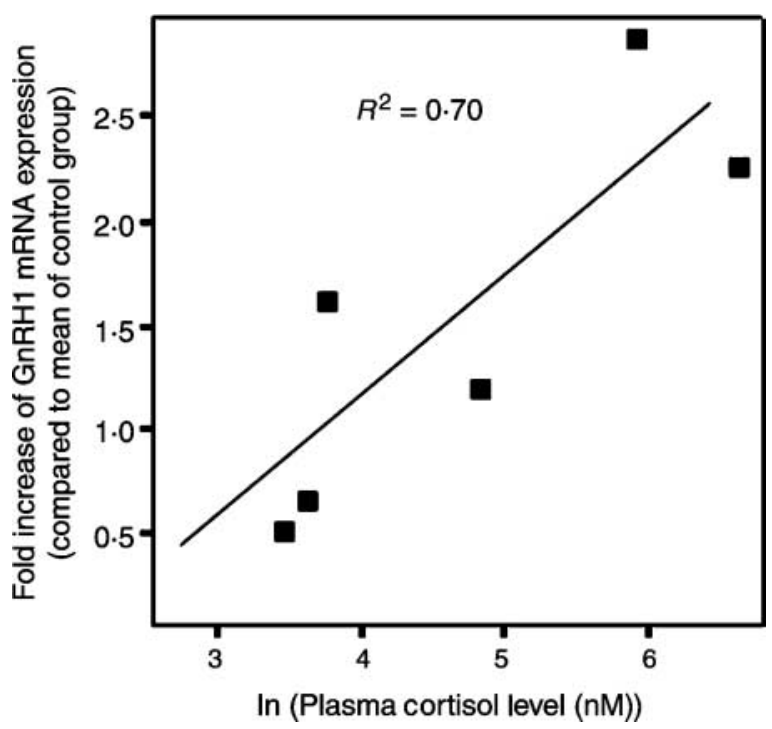

Figure. 4 Correlation between GnRH1 mRNA level and plasma cortisol in 24-h social suppression. attempt to preserve the HPG axis, in case social opportunity arises again. It has been postulated that such resistance to the negative effects of social stress as measured in the HPG axis might make sense in some cases (Wingfield \& Sapolsky 2003). Animals with limited time to reproduce, such as $A$. burtoni, for example, would mount a defense against social descent to extend reproductive opportunities. Other experiments have shown that changes in social hierarchy occur regularly in A. burtoni (Hofmann et al. 1999), so it is possible that animals resist the down-regulation of GnRH1 mRNA in anticipation of a possible quick return to social dominance. In some species, there are distinct coping strategies such as displaced aggression that can reduce the stress response (e.g. Houston 1972, Davis \& Levine 1982, Clement et al. 2005) although the mechanisms of these are unknown.

During the social descent produced in this experiment, many physiological systems are pitted against one another in the service of homeostasis. As the animal spends energy to bring its behavioral and physiological systems under control, it may be attempting to preserve the status quo, in case there is a chance for return to high status. Given this perspective, assuming that gene translation mirrors gene transcription, it is surprising that testosterone output was decreased, as this reflects a neutralization of the GnRH1 expression upregulation. We do not know whether the physiological defense we observe is maintained for more than $24 \mathrm{~h}$. Further, there are several possible mechanisms through which the effect of cortisol on GnRH1 gene expression might operate; however, understanding how this occurs at the cellular level will require further experiments. It seems likely that this glimpse of a physiological defense may be part of a complex response to social descent mounted by the animal.

\section{Acknowledgements}

We thank Drs A K Greenwood, R Henderson and S Zhao for technical help, and Dr L. Harbott for comments on earlier versions of the manuscript. Thanks also to L Grosenick for help with statistical analyses and to C Chen, J Martin and L Ozowara for experimental assistance. Supported by an HHMI grant to VNP, NIH NS 34950 Javits Award to R D F, and NRSA F32MHO68175 to T S C. The authors declare that there is no conflict of interest that would prejudice the impartiality of this scientific work.

\section{References}

Au T, Greenwood AK \& Fernald RD 2006 Differential social regulation of two pituitary gonadotropin-releasing hormone receptors. Behavioural Brain Research (in press).

Becker JS, Breedlove SM, Crews D \& McCarthy M 1992 Behavioral Endocrinology. 2nd edn, pp 411-413. Cambridge, MA and London: Bradford Books.

Blanchard DC, Sakai RR, McEwen B, Weiss SM \& Blanchard RJ 1993 Subordination stress: behavioral, brain, and neuroendocrine correlates. Behavioural Brain Research 58 113-121. 
Borg B 1994 Androgens in teleost fishes. Comparative Biochemistry and Physiology 109C 219-245.

Burmeister SS \& Fernald RD 2005 Evolutionary conservation of the egr-1 immediate-early gene response in a teleost. Journal of Comparative Neurology 481 220-232.

Chandran UR, Attardi B, Friedman R, Dong KW, Roberts JL \& DeFranco DB 1994 Glucocorticoid receptor-mediated repression of gonadotropinreleasing hormone promoter activity in GT1 hypothalamic cell lines. Endocrinology 134 1467-1474.

Chen C-C \& Fernald RD 2006 Distribution of two GnRH receptor types in a teleost suggests functional specialization. Journal of Comparative Neurology $495314-323$

Clement TS, Parikh V, Schrumpf M \& Fernald RD 2005 Behavioral coping strategies in a cichlid fish: the role of social status and acute stress response in direct and displaced aggression. Hormones and Behavior 47 336-342.

Davis H \& Levine S 1982 Predictability, control, and the pituitary-adrenal response in rats. Journal of Comparitive Physiology and Psychology 96 393-404.

Davis MR \& Fernald RD 1990 Social control of neuronal soma size. Journal of Neurobiology 21 1180-1188.

De Goeij DC, Dijkstra H \& Tilders FJ 1992 Chronic psychosocial stress enhances vasopressin, but not corticotropin-releasing factor, in the external zone of the median eminence of male rats: relationship to subordinate status. Endocrinology 131 847-853.

Fernald RD 2002 Social regulation of the brain: sex, size and status. In The Genetics and Biology of Sex Determination, pp 169-186. Ed. R Short. Chichester: Wiley.

Fernald RD \& Hirata NR 1977 Field study of haplochromis-burtoni habitats and cohabitants. Environmental Biology of Fishes 2 299-308.

Fox HE, White SA, Kao MH \& Fernald RD 1997 Stress and dominance in a social fish. Journal of Neuroscience 17 6463-6469.

Fraley NB \& Fernald RD 1982 Social control of developmental rate in the African sichlid haplochromis burtoni. Zeitschrift fuer Tierpsychologie 60 66-82.

Greenwood AK, Butler PC, White RB, DeMarco U, Pearce D \& Fernald RD 2003 Multiple corticosteroid receptors in a teleost fish: Distinct sequences, expression patterns, and transcriptional activities. Endocrinology 144 $4226-4236$.

Grens KE, Greenwood AK \& Fernald RD 2005 Two visual pathways are targeted by gonadotropin releasing hormone in the retina. Brain, Behaviour and Evolution 66 1-9.

Hofmann HA, Benson ME \& Fernald RD 1999 Social status regulates growth rate: consequences for life-history strategies. PNAS 96 14171-14176.

Houston BK 1972 Control over stress, locus of control, and response to stress. Journal of Personality and Social Psychology 21 249-255.

Manogue KR, Leshner AI \& Candland DK 1975 Dominance status and adrenocortical reactivity to stress in squirrel monkeys (Saimiri sciureus). Primates 16 457-463.
Maya-Nunez G \& Conn PM 2003 Transcriptional regulation of the $\mathrm{GnRH}$ receptor gene by glucocorticoids. Molecular and Cellular Endocrinology 200 89-98.

McEwen BS \& Wingfield JC 2003 The concept of allostasis in biology and biomedicine. Hormones and Behavior $432-15$.

Oliveira RF, McGregor PK \& Latruffe C 1998 Know thine enemy: fighting fish gather information from observing conspecific interactions. Proceedings of Biological Science 265 1045-1049.

Oliveira RF, Lopes M, Carneiro LA \& Canario AV 2001 Watching fights raises fish hormone levels. Nature 409475.

Oliveira RF, Hirschenhauser K, Carneiro LA \& Canario AV 2002 Social modulation of androgen levels in male teleost fish. Comparative Biochemistry and Physiology. Part B, Biochemistry and Molecular Biology 132 203-215.

Oliveira RF, Carneiro LA \& Canario AV 2005 Behavioural endocrinology: no hormonal response in tied fights. Nature 437 207-208.

Parikh VN, Clement TS \& Fernald RD 2006 Androgen level and male social status in the African cichlid, Astatotilapia burtoni. Behavioural Brain Research $166291-295$.

Sapolsky RM 1993a Endocrinology alfresco: psychoendocrine studies of wild baboons. Recent Progress in Hormone Research 48 437-468.

Sapolsky RM 1993 In Primate Social Conflict, pp 171-183. Eds W Mason \& S Mendoza. New York: SUNY Press.

Sapolsky RM 2005 The influence of social hierarchy on primate health. Science 308 648-652.

Weiss JM 1971 Effects of coping behavior with and without a feedback signal on stress pathology in rats. Journal of Comparitive Physiology and Psychology 77 22-30.

Weiss JM, Goodman PR, Lostio BG, Corrigan S, Charry JM \& Bailey WH 1981 Stressor relationship to norepinephrine, dopamine and serotonin levels in various regions of rat brain. Brain Research Reviews 3 167-205.

Wendelaar Bonga S 1997 The stress response in fish. Physiological Reviews 77 592-625.

White SA, Nguyen T \& Fernald RD 2002 Social regulation of gonadotropinreleasing hormone. Journal of Experimental Biology 205 2567-2581.

Wingfield JC \& Sapolsky RM 2003 Reproduction and resistance to stress: when and how. Journal of Neuroendocrinology 15 711-724.

Zhao S \& Fernald RD 2005 Comprehensive algorithm for quantitative realtime polymerase chain reaction. Journal of Computational Biology $\mathbf{1 2}$ 1047-1064.

Received in final form 23 March 2006

Accepted 28 March 2006

Made available online as an Accepted Preprint 25 April 2006 